\title{
Análise e Implantação de Repositório Digital Utilizando Software Livre DSPACE
}

\author{
Lucas Salviano Romani ${ }^{1}$, Elvis Fusco ${ }^{2}$, Plácida L. V. Amorim da Costa Santos ${ }^{3}$ \\ ${ }^{1,2}$ Centro Universitário Eurípides de Marília (UNIVEM) \\ Marília - SP - Brazil \\ ${ }^{3}$ Programa de Pós-Graduação em Ciência da Informação \\ Universidade Estadual Paulista (UNESP) - Marília - SP - Brazil \\ \{lucao, fusco\}@univem.edu.br, placida@marilia.unesp.br
}

\begin{abstract}
The great part of educational institutions uses computational ways to generate digital documents. However, the most part of these documents are not being avaiable to those people who are interested in them. The purpose of this article is to present the using of the digital repositories, aiming the development of a digital repository able to ensure that the knowledge generated by the Research Group - New Tecnologies in Information from the Post-Graduation in Information Science Program in Marilia Campus can be preserved in time and efficiently being available to all who are interested. And after this study, it will demonstrate the using of digital repositories on the management of digital documents in companies and in educational and research institutions.
\end{abstract}

Resumo. Grande parte das instituições de ensino utiliza meios computacionais para geração de documentos digitais. Entretanto, a maior parte destes documentos deixa de ser disponibilizado para aquelas pessoas as quais eles interessam. Este artigo tem como objetivo a apresentação do uso dos repositórios digitais, com o intuito do desenvolvimento de um ambiente informacional capaz de fazer com que o conhecimento gerado pelo Grupo de Pesquisa - Novas Tecnologias em Informação do Programa de Pós-Graduação em Ciência da Informação da UNESP de Marília seja preservado no tempo e disponibilizado a todos os interessados de maneira eficiente e, a partir deste estudo, demonstrar o uso de repositórios digitais na gestão de documentos digitais em empresas e instituições de ensino e pesquisa.

\section{Introdução}

Com o uso intenso de meios computacionais para criação de produções científicas e documentos de uso geral, muita informação tem sido gerada, mas grande parte deixa de ser disseminada para aquelas pessoas e instituições as quais ela interessa e também documentos acabam sendo perdidos e precisam ser refeitos, sendo que poderiam ser facilmente reutilizados, provendo assim economia de tempo e pessoal nas organizações.

Atualmente muitas instituições de ensino e de pesquisa utilizam sistemas computacionais para gerenciar suas produções científicas, as quais são criadas nos mais diversos tipos de arquivos, como arquivos de texto (artigos, dissertações, relatórios, livros, teses, entre outros), planilhas eletrônicas, softwares, imagens, códigos fonte, arquivos de áudio, arquivos de vídeo, páginas web, entre outros. Tais produções muitas 
vezes não são geridas adequadamente, o que leva a não serem preservadas no tempo e não serem disponibilizadas aqueles que possuem interesse em acessar tais produções, o que diminui as possibilidades de se ter maior proveito e consequentemente maior visibilidade desses documentos digitais.

Tais informações necessitam serem armazenadas para que não sejam perdidas no tempo, para que possam ser acessadas pelos interessados e para que sejam preservadas a fim de se permitir o reuso dos documentos criados pelas instituições. Desta maneira, segundo Lewis e Yates (2008) faz-se necessário o uso de sistemas capazes de suprir estas necessidades, e para tais necessidades são apresentados os repositórios digitais, sistemas capazes de armazenar, gerir, disseminar e preservar as produções de uma instituição qualquer.

Este artigo tem como objetivo fazer uso de sistemas de informação para que as produções científicas e os documentos gerados pelas instituições e organizações sejam disponibilizados aos usuários interessados e estes tenham facilidade em acessá-los. Para isso pretende-se demonstrar o desenvolvimento e a customização de um repositório digital utilizando softwares livres para atender as necessidades de armazenamento e disseminação das produções científicas geradas pelo Grupo de Pesquisa - Novas Tecnologias em Informação (GP-NTI) do Programa de Pós-Graduação em Ciências da Informação da UNESP de Marília.

Além de permitirem que os conhecimentos gerados em instituições de ensino e pesquisa sejam de fato capazes de se tornarem conhecimentos explícitos para fins de pesquisas e de criação de novos conhecimentos, os repositórios digitais também encontram utilidade em empresas de modo geral, pois possuem a capacidade de transformar conhecimento tácito em conhecimento explícito, ou seja, empresas que utilizam repositórios digitais para armazenar, preservar e disponibilizar seus documentos digitais poderão ter seus documentos amplamente divulgados e mais utilizados pelos interessados.

Uma vez socializados, os documentos digitais criados por seus membros tendem a se tornarem conhecimentos explícitos e poderão permitir que outros membros da instituição além dos criadores dos documentos os usem e com isso aumentem o conhecimento geral da organização e consecutivamente alcancem melhorias em seus processos, com maior ganho de tempo e agilidade nos cumprimentos de tarefas.

\section{Repositórios Digitais}

Com a evolução da tecnologia, o suporte às informações modificou-se muito e as produções científicas passaram a ser desenvolvidas em sua grande maioria através do uso de meios computacionais. Surgiu então a necessidade de se desenvolver sistemas capazes de armazenar tais produções, estando elas em qualquer dos formatos existentes, tais como arquivos de texto, vídeos, imagens, sons, entre tantos outros, e também preservá-los no tempo e prover acesso a todos os interessados.

O grande aumento da capacidade de armazenamento dos computadores e a evolução da Internet e das redes tornou possível pensar-se em repositórios digitais capazes de permitir o acesso ao conteúdo integral das obras em formato digital. Barton (2005) define repositórios institucionais como sendo "um banco de dados com um conjunto de serviços para capturar, armazenar, indexar, preservar e distribuir a pesquisa de uma instituição de ensino em formatos digitais". 
Repositórios digitais são conjuntos de obras em vários formatos diferentes, mas digitais, disponíveis para serem acessadas através de meios computacionais, podendo ser acessados a partir de redes de computadores locais ou pela internet. O conteúdo dos repositórios digitais não possui limitações, podendo existir repositórios institucionais, que agrupam projetos de pesquisas, teses de pós-graduação, trabalhos diversos desenvolvidos pelos membros da instituição, monografias, entre outros, e também repositórios para qualquer tipo de arquivos em formato digital que se deseje.

Tratando-se de repositórios institucionais de universidades Lynch (2003) os define como sendo um conjunto de serviços que uma instituição de ensino oferece aos membros de sua comunidade, objetivando o gerenciamento e disseminação eficiente dos materiais digitais gerados pela instituição e pelos membros de sua comunidade.

Ainda, segundo Lynch (2003), é um compromisso da instituição a preservação a longo prazo dos materiais digitais armazenados em seus repositórios digitais, quando tal preservação for apropriada, bem como também sua organização adequada e o acesso ou distribuição deste materiais.

Os repositórios digitais institucionais, segundo definição do glossário elaborado pelo IBICT (Instituto Brasileiro de Informação em Ciência e Tecnologia), são sistemas de informação que permitem o armazenamento, preservação, divulgação e dão acesso à produção intelectual de comunidades universitárias. Ao fazê-lo, intervêm em duas questões estratégicas: contribuem para o aumento da visibilidade e o "valor" público das instituições, servindo como indicador tangível da sua qualidade; permitem a reforma do sistema de comunicação científica, expandindo o acesso aos resultados da investigação e reassumindo o controle acadêmico sobre a publicação científica [Repositório institucional, 2007].

Repositórios institucionais são conjuntos de serviços oferecidos pelas instituições para gerenciamento e disseminação dos materiais digitais criados pela instituição e pelos membros da sua comunidade, provendo acesso aos materiais digitais tanto para os membros internos da instituição quanto para os externos, através da internet, que também possuam interesse em tais materiais.

Rodrigues et al. (2006), Lynch (2003) e Crow (2002) afirmam que os repositórios digitais institucionais permitem que grande parte do conhecimento de uma instituição seja reunido, preservado e disseminado de forma eficiente, contribuindo desta maneira para o aumento da visibilidade das produções da instituição.

Afirmam que dentro dos últimos anos o número de repositórios digitais disponíveis tem crescido consideravelmente, especialmente na comunidade universitária, com objetivos focados no gerenciamento, na preservação, no armazenamento e também na divulgação das produções intelectuais desta comunidade. Instituições de ensino e pesquisa possuem interesse que seus membros disponibilizem suas produções científicas em tais repositórios digitais institucionais, uma vez que ao disponibilizarem tais produções, estão contribuindo diretamente para que as instituições tenham a possibilidade de ganhar mais prestígio e também credibilidade dento da comunidade científica, além de contribuir efetivamente com o progresso científico.

A necessidade de se preservar digitalmente documentos, que antes se encontravam apenas em papel, e permitir que os mesmos estejam acessíveis a qualquer 
pessoa, tem levado determinadas organizações, como universidades e bibliotecas, entre outras, a criar os seus próprios repositórios [Santos; Teixeira; Pinto; 2005].

Segundo Barton (2005) um sistema de repositório institucional não é somente definido pelo software e pelo banco de dados que contêm as coleções digitais. Um repositório institucional é um conjunto de serviços para aqueles que depositam material para as comunidades de pesquisa e escolares envolvidas e para os usuários finais. Portanto um repositório institucional é constituído pelo software, pessoal responsável pelo gerenciamento do repositório e pelo seu conteúdo.

Os repositórios digitais utilizam-se de metadados para permitir a busca e recuperação de seus objetos digitais e possibilitar a interoperabilidade com outras bases de dados.

\section{Análise de Ferramentas de Construção de Repositórios Digitais}

Foram analisadas algumas ferramentas open source disponíveis para implementação de repositórios digitais. Todas as ferramentas analisadas possuem interface Web e são softwares livres, por isso tais características não serão tratadas repetidamente, apesar de ocorrem comentários a respeito dos tipos de licenças destes softwares e também dos layouts de suas interfaces.

Alguns requisitos de software são indispensáveis para o repositório digital proposto de acordo com as necessidades funcionais do grupo de pesquisa e, portanto, foram analisados individualmente, enquanto que os requisitos apenas desejáveis foram analisados e comentados durante as descrições de cada ferramenta.

A análise e descrição dos aplicativos levaram em conta os seguintes aspectos:

- Histórico de desenvolvimento e uso do software;

- Estrutura do repositório;

- Formatos de arquivos suportados;

- Opções e métodos de busca;

- Processo de submissão de arquivos:

- Opção de navegação pelas coleções existentes;

- Interação com o usuário;

- Documentação existente;

- Processo de inclusão dos metadados dos arquivos;

- Protocolos de comunicação e interoperabilidade suportados;

- Métodos de importação e exportação de metadados.

\subsection{Comparação dos Aplicativos}

Os softwares DSpace, CDSWare, Nou-Rau e Greenstone tiveram uma análise de suas funções devido ao fato de a documentação dos mesmos ter demonstrado que teriam as funcionalidades necessárias para suprir as necessidades de um repositório digital para o 
objetivo que está sendo proposto, que seria um repositório digital para um grupo de pesquisas.

A Tabela 1 demonstra a lista dos requisitos necessários para que o software atenda as necessidades do repositório digital proposto.

Estes requisitos serão cruciais na escolha do software para desenvolvimento do repositório digital proposto, pois o não cumprimento de algum destes requisitos por algum dos softwares analisados irá eliminá-lo automaticamente da lista de possíveis softwares a serem utilizados, uma vez que sem o cumprimento integral destes requisitos obrigatórios, muito provavelmente o uso deles implicará problemas tanto na fase de desenvolvimento quanto para os usuários finais do repositório digital.

\section{Tabela 1 - Atendimento dos requisitos obrigatórios para o repositório digital proposto nos aplicativos analisados}

\begin{tabular}{|c|c|c|c|c|}
\hline \multirow[b]{2}{*}{ Requisitos obrigatórios } & \multicolumn{4}{|c|}{ Softwares } \\
\hline & DSpace & CDSWare & Nou-Rau & Greenstone \\
\hline Software livre & A & $\mathbf{A}$ & $\mathbf{A}$ & $\mathbf{A}$ \\
\hline Interface web & $\mathbf{A}$ & $\mathbf{A}$ & $\mathbf{A}$ & $\mathbf{A}$ \\
\hline $\begin{array}{l}\text { Permite inclusão de mais um formato de } \\
\text { arquivo por obra }\end{array}$ & A & $\mathbf{A}$ & NA & A \\
\hline Utilização simples e intuitiva & $\mathbf{A}$ & $\mathbf{A}$ & $\mathbf{A}$ & $\mathbf{A}$ \\
\hline Possibilita criação de coleções distintas & $\mathbf{A}$ & $\mathbf{A}$ & $\mathbf{A}$ & $\mathbf{A}$ \\
\hline $\begin{array}{l}\text { Possibilita navegação pelos campos autor, } \\
\text { título, assunto ou data. }\end{array}$ & $\mathbf{A}$ & $\mathbf{A}$ & $\mathbf{A}$ & $\mathbf{A}$ \\
\hline $\begin{array}{l}\text { Permite busca por autor, título, assunto e por } \\
\text { palavras-chave }\end{array}$ & $\mathbf{A}$ & $\mathbf{A}$ & $\mathbf{A}$ & $\mathbf{A}$ \\
\hline Permite submissão pelo próprio autor & $\mathbf{A}$ & $\mathbf{A}$ & $\mathbf{A}$ & NA \\
\hline $\begin{array}{l}\text { A inclusão de metadados segue algum } \\
\text { padrão aceito internacionalmente }\end{array}$ & $\mathbf{A}$ & $\mathbf{A}$ & $\mathbf{A}$ & $\mathbf{A}$ \\
\hline $\begin{array}{l}\text { Permite importação e exportação de obras e } \\
\text { metadados }\end{array}$ & $\mathbf{A}$ & $\mathbf{A}$ & $\mathbf{A}$ & $\mathbf{A}$ \\
\hline $\begin{array}{l}\text { Possui interação com usuário, através de } e \text { - } \\
\text { mail e informações no repositório }\end{array}$ & $\mathbf{A}$ & $\mathbf{A}$ & $\mathbf{A}$ & NA \\
\hline Documentação existente é satisfatória & $\mathbf{A}$ & $\mathbf{A}$ & NA & $\mathbf{A}$ \\
\hline $\mathrm{A}=$ atende requisito; & $\mathrm{NA}=$ não & tende requi & & \\
\hline
\end{tabular}

A Tabela 2 apresenta uma lista dos requisitos desejáveis, mas não obrigatórios dos softwares analisados. Estes requisitos não são obrigatórios, mas tem peso importante na escolha do software a ser utilizado no desenvolvimento do repositório digital. 


\section{Tabela 2 - Atendimento dos requisitos desejáveis para o repositório digital proposto nos aplicativos analisados}

\begin{tabular}{|c|c|c|c|c|}
\hline \multirow[b]{2}{*}{ Requisitos desejáveis } & \multicolumn{4}{|c|}{ Softwares } \\
\hline & DSpace & CDSWVare & Nou-Rau & Greenstone \\
\hline $\begin{array}{l}\text { Não precisar de plugins instalados na } \\
\text { máquina do usuário final }\end{array}$ & $\mathbf{A}$ & $\mathbf{A}$ & $\mathbf{A}$ & $\mathbf{A}$ \\
\hline $\begin{array}{l}\text { Possui comportamentos distintos para } \\
\text { tratamento de coleções distintas }\end{array}$ & $\mathbf{A}$ & $\mathbf{A}$ & NA & $\mathbf{A}$ \\
\hline $\begin{array}{l}\text { Interface agradável ao usuário e } \\
\text { personalizável segundo as necessidades }\end{array}$ & $\mathbf{A}$ & $\mathbf{A}$ & $\mathbf{A}$ & $\mathbf{A}$ \\
\hline $\begin{array}{l}\text { Possui hierarquia entre as coleções do } \\
\text { repositório }\end{array}$ & $\mathbf{A}$ & $\mathbf{A}$ & $\mathbf{A}$ & $\mathbf{A}$ \\
\hline $\begin{array}{l}\text { Possibilidade de navegação por vários } \\
\text { campos, além de autor, título, assunto ou } \\
\text { data. }\end{array}$ & NA & $\mathbf{A}$ & NA & $\mathbf{A}$ \\
\hline $\begin{array}{l}\text { Permiti buscas avançadas fazendo a } \\
\text { combinação de elementos de metadados e } \\
\text { texto-integral (full-text). }\end{array}$ & $\mathbf{A}$ & $\mathbf{A}$ & NA & NA \\
\hline Possui mecanismos de workflow básicos & $\mathbf{A}$ & $\mathbf{A}$ & $\mathbf{A}$ & NA \\
\hline $\begin{array}{l}\text { Permite a interoperabilidade de maneira } \\
\text { automática com outros sistemas na mesma } \\
\text { base ou em bases distintas }\end{array}$ & $\mathbf{A}$ & $\mathbf{A}$ & NA & $\mathbf{A}$ \\
\hline $\begin{array}{l}\text { Permite configuração de uso de vocabulários } \\
\text { controlados }\end{array}$ & $\mathbf{A}$ & NA & NA & $\mathbf{A}$ \\
\hline $\begin{array}{l}\text { Permitir exportação de coleções ou parte } \\
\text { delas para consulta local do usuário. }\end{array}$ & $\mathbf{A}$ & NA & NA & $\mathbf{A}$ \\
\hline $\begin{array}{l}\text { Permite utilização de protocolos } \\
\text { automatizados para realização de troca de } \\
\text { registros }\end{array}$ & $\mathbf{A}$ & $\mathbf{A}$ & $\mathbf{A}$ & NA \\
\hline Permite uso de identificadores persistentes & $\mathbf{A}$ & NA & NA & NA \\
\hline $\begin{array}{l}\text { Permite gerar relatórios de estatísticas de } \\
\text { utilização }\end{array}$ & $\mathbf{A}$ & $\mathbf{A}$ & $\mathbf{A}$ & NA \\
\hline
\end{tabular}

Após estudo dos softwares disponíveis, das teorias de metadados, interoperabilidade e dos repositórios digitais e também análise dos requisitos e necessidades do sistema proposto juntamente aos integrantes do GP-NTI ficaram definidos alguns padrões e características necessárias no repositório proposto, e partindo destas premissas ocorreu a definição de qual ferramenta utilizar como sistema para o repositório digital proposto.

O padrão de metadados adotado para descrição dos objetos digitais do repositório foi o Dublin Core e os motivos que levaram a esta escolha foram os seguintes:

- O nível de detalhamento dos metadados dos recursos submetidos ao repositório proposto não precisam ser excessivamente aprofundados;

- A utilização do padrão Dublin Core é simples e bastante intuitiva, o que torna fácil o entendimento dos profissionais das diversas áreas abrangidas pelo repositório, que estarão submetendo itens no repositório; 
- O padrão Dublin Core é o padrão para as trocas de informações e capacidade de interoperabilidade previstas pela OAI (NSDL, 2005).

Os softwares Nou-rau e o Greenstone foram eliminados devido ao fato de não atenderem a todos os requisitos obrigatórios (Tabela 1).

Além de o Greenstone não preencher tais requisitos, também fortaleceu a decisão de eliminá-los devido ao fato de a interface do administrador do sistema não poder ser executada diretamente do browser e a submissão inicial dos documentos precisa ser realizada também pelo administrador do sistema, o que não seria possível de ser atendido no repositório proposto.

No Nou-rau existe também a dificuldade da escassez de documentação técnica e percebe-se que o desenvolvimento de atualizações e novas versões para melhoria do sistema não tem recebido a atenção necessária, pois sistemas web precisam estar em constante atualização e melhoria para que atendam as necessidades dos usuários. Outra dificuldade encontrada no Nou-rau é o fato de cada obra poder conter apenas um arquivo associado.

Portanto restaram apenas o DSpace e CDSWare como candidatos para adoção no desenvolvimento do repositório proposto, pois ambos atenderam todos os requisitos obrigatórios propostos. O CDSWare possui como grande vantagem seu mecanismo de busca muito poderoso e a existência de muitas opções de interação com o usuário do sistema.

O DSpace possui como grandes diferenciais o constante desenvolvimento e melhoria de seus sistemas, a utilização de identificadores persistentes, uma documentação extensa e uma comunidade de desenvolvedores e de instituições de ensino e empresas superior em quantidade a qualquer outro sistema analisado (Figura $1)$.

Uma desvantagem do DSpace sobre o CDSWare seria seu sistema de busca mais simples, mas que não é simples para os objetivos do repositório proposto e atenderia perfeitamente suas necessidades.

Os pontos fortes do DSpace, em principal o fato de ser o sistema de repositórios digital mais utilizado no mundo e de o mesmo possuir mais recursos que o CDSware, pesaram muito na escolha e portanto o DSpace foi o software escolhido para a realização do desenvolvimento do repositório digital proposto.

\section{DSpace}

DSpace é um sistema de repositórios digitais Open Source, baseado no modelo de licença BSD (Berkeley Software Distribution), desenvolvido pelo MIT (Massachussets Institute of Technology) em parceria com a HP (Hewllet-Packard) e está disponível no próprio site do DSpace (http://www.dspace.org). Seu nome completo é Digital Space Institucional Digital Repository System.

Atualmente é a ferramenta para construção de repositórios digitais institucionais mais usada internacionalmente, segundo dados do OpenDOAR (http://www.opendoar.org/index.html) e do ROAR (http://roar.eprints.org/index.php), sites responsáveis por indexar os repositórios digitais existentes em todo o mundo e fornecer dados, números e gráficos a respeito do uso dos mesmos. A Figura 1 mostra o 
número de repositórios criados em várias ferramentas disponíveis diferentes disponíveis, e reforça a afirmação de que o DSpace é a mais usada entre elas.

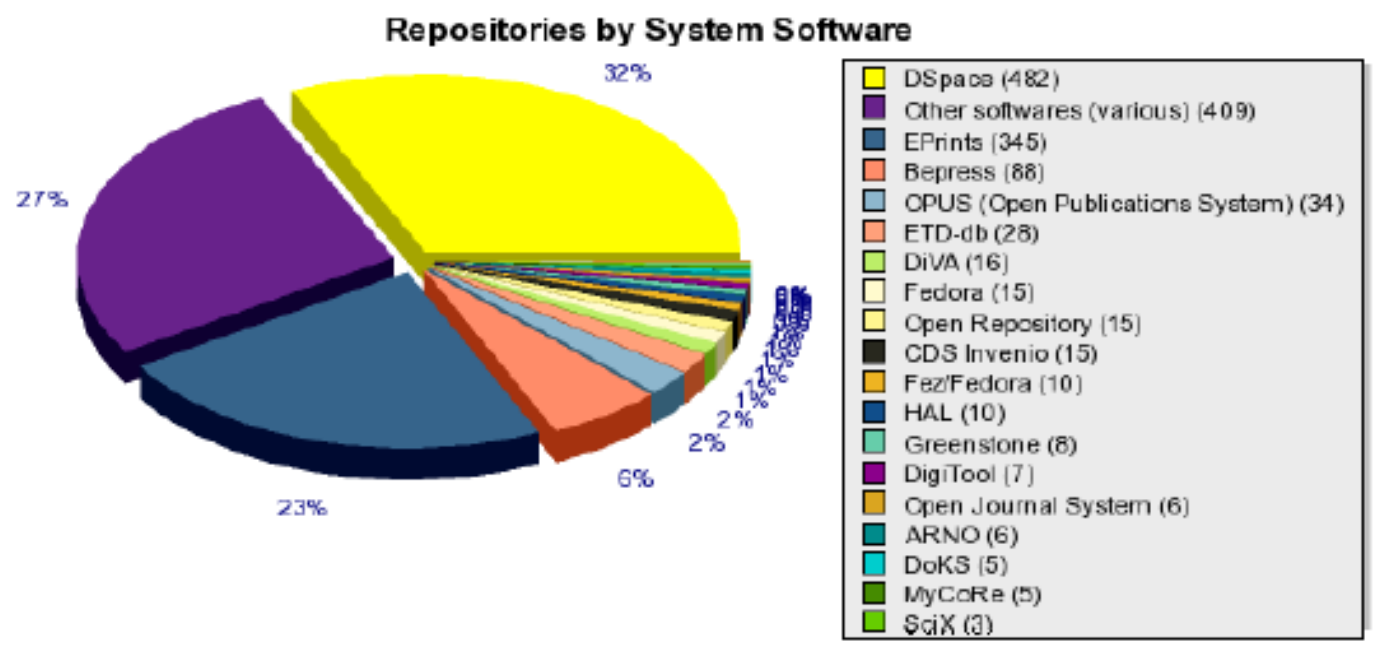

Figura 1 - Quantidade de repositórios desenvolvidos por cada sistema

Fonte: http://roar.eprints.org

De acordo com Lews e Yates (2008), o DSpace captura, distribui e também preserva objetos digitais. Os autores relatam que o DSpace é uma plataforma que permite capturar itens em qualquer formato - texto, vídeo, áudio e dados, e os distribui por meio da web, indexando o trabalho, permitindo aos usuários poderem procurar e recuperar os itens. Nesse sentido, ele preserva os trabalhos digitais a longo prazo. Os autores também relatam que o DSpace possui três objetivos principais, que são os seguintes:

- Facilitar a captura e inserção dos materiais, incluindo os metadados sobre os materiais;

- Facilitar o acesso fácil ao material, tanto por listagens quanto por buscas;

- Facilitar a preservação a longo prazo dos materiais.

O DSpace encontra-se atualmente na versão 1.5.2, atualização lançada no ano de 2009. Sua primeira versão, a 1.0 foi lançada em novembro de 2002 e a partir daí a cada ano foi lançada uma nova versão, sendo a versão 1.1 em maio de 2003 , a versão 1.2 em agosto de 2004, a versão 1.3 em agosto de 2005, a versão 1.4 em julho de 2006 e no único caso que passou do período de um ano em março de 2008 foi lançada a versão 1.5. Uma nova versão, a 1.6 já se encontra em fase de estudos.

Uma das maiores vantagens do DSpace é o fato de ele suportar todos os tipos de formatos digitais. Alguns exemplos são: Documentos (artigos, preprints, relatórios tecnicos, dissertações); Livros; Teses; Visualizações, simulações e outros modelos; Softwares; Publicações multimídia; Imagens; Arquivos de áudio; Arquivos de vídeo; Páginas web; entre outros.

A DSpace Foundation é uma fundação sem fins lucrativos fundada em 2007 para prover o crescimento da comunidade de instituições que adotam o DSpace. A 
missão da fundação é liderar o desenvolvimento colaborativo do software open source para possibilitar o permanente acesso as produções digitais. distintas:

O DSpace é formado por diversos componentes, distribuídos por três camadas

- A Storage Layer que é responsável pelo armazenamento físico dos metadados e dos conteúdos;

- A Business Logic Layer que trata da gestão dos conteúdos do arquivo, dos utilizadores, das políticas de autorização e do workflow e;

- A Application Layer que contém os componentes que comunicam com o mundo exterior, como por exemplo a interface web do utilizador e o serviço de suporte ao protocolo de coleta de metadados da OAI.

Cada camada da arquitetura invoca apenas a camada imediatamente inferior, por exemplo, a Application Layer não pode invocar diretamente a Storage Layer. Cada componente da Business Logic Layer e da Storage Layer possuem uma API.

Estas API's são classes, objetos e métodos em Java. O conjunto das API ${ }^{\text {ee }}$ públicas dos diversos componentes de cada camada, forma aquilo que se designa por Layer API e possui as designações de Storage API e DSpace Public API.

Esta preocupação em manter a arquitetura de três camadas do DSpace está presente na própria organização do código fonte, que está coerentemente repartido em três pacotes, que correspondem estritamente a cada uma das camadas. O pacote org.dspace.app que implementa a Application Layer, o pacote org.dspace.Business que implementa a Logic Layer e o pacote org.dspace.storage que implementa a Storage Layer.

Para seu correto funcionamento, o DSpace na versão mais recente, a 1.5.2, necessita dos seguinte pré-requisitos de softwares:

- Sistema Operacional: Windows ou UNIX-like.

- Servidor Web: Apache Tomcat 5.X ou mais novo.

- Banco de Dados: PostgreSQL 8.X ou mais novo ou Oracle 9 ou mais novo.

- Adicionais: Apache ANT 1.6.2 ou mais novo, Java SDK 1.5 ou mais novo e Apache Maven 2.0.8 ou mais novo.

\section{Customização do Repositório Digital}

Após a instalação do software DSpace, foram feitas customizações para que o repositório atendesse as necessidades informacionais dos usuários do Grupo de Pesquisa. Para realização das customizações no repositório digital a partir da interface de administrador, o usuário deve estar logado no sistema com a conta de administrador. Logado como administrador foi acessada a área de Administrador, mostrada na Figura 2.

A partir desta interface podem ser realizadas ações como: criação das comunidades, sub-comunidades e coleções do repositório, cadastro de novos utilizadores do sistema, criação de novos grupos de usuários do sistema, dividindo os 
com relação as suas funções, alteração de registros (Handle), alteração dos metadados padrão do Dublin Core, alteração dos formatos de bitstreams conhecidos, acessar os processos de workflow pendentes, administrar as políticas de permissões do repositório, editar as notícias, tanto as laterais quanto as superiores, editar o arquivo de licença padrão do repositório, alterar as ordens de administração dos supervisores e visualizar as estatísticas, quando estas estiverem disponíveis no repositório.

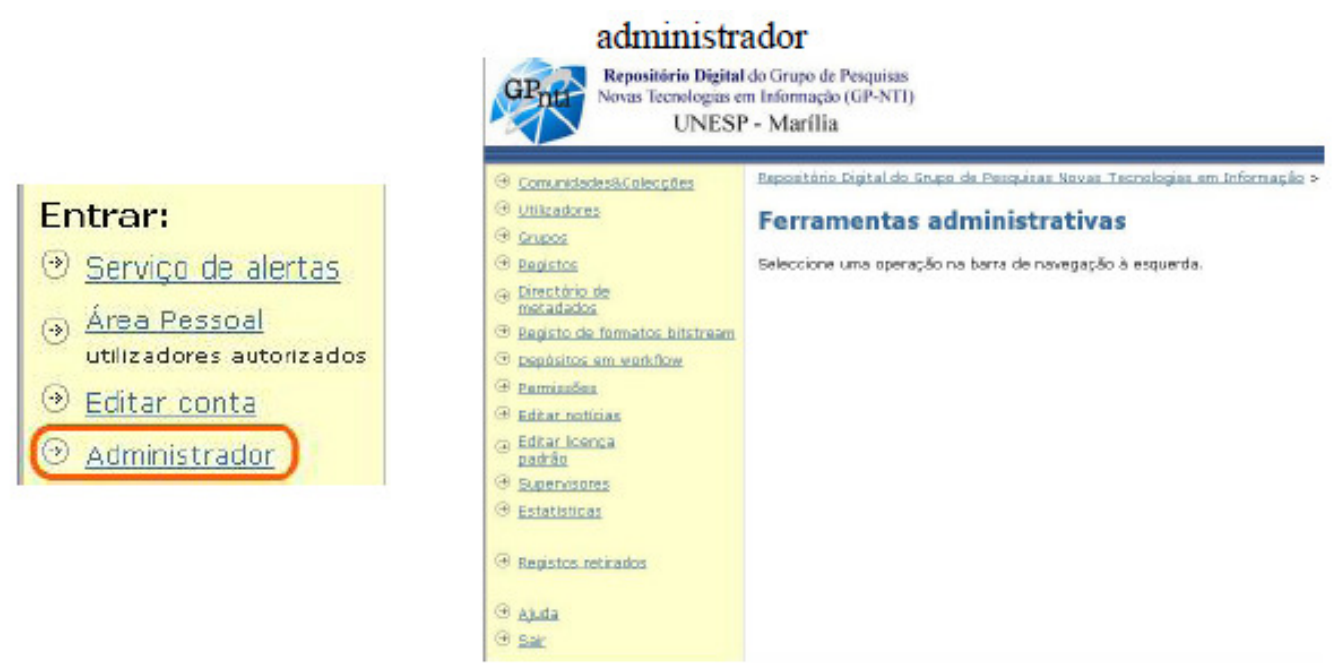

Figura 2 - Customização do Repositório Digital

A partir dos requisitos apresentados pelos membros do Grupo de Pesquisa, foram criadas quatro comunidades iniciais para o repositório proposto e para cada uma delas foram criadas algumas coleções ditas como necessárias pelos membros. A Figura 33 mostra a tela de criação de novas comunidades e também a hierarquia que se formou no repositório após a criação das comunidades e de suas respectivas coleções.

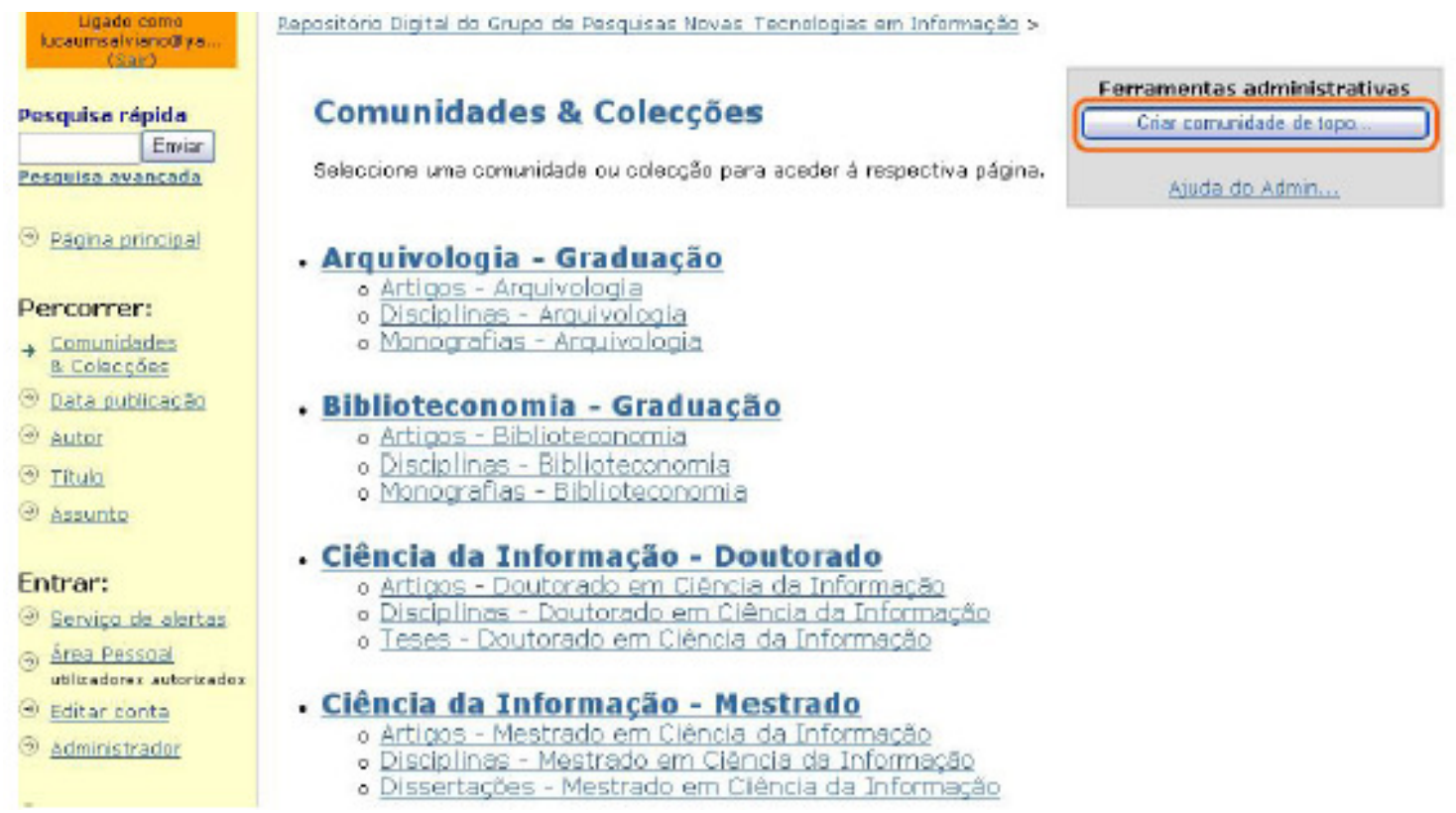

Figura 3 - Estrutura das Comunidades e Coleções do Repositório 
Todas as modificações e customizações realizadas no repositório digital proposto foram testadas nos navegadores Internet Explorer, na versão 8, Mozilla Firefox, na versão 3.5.5 e Google Chrome, na versão 3.0.195.33, e em todos os navegadores os resultados foram considerados satisfatórios, sem fornecer perda alguma das características e funcionalidades do repositório proposto.

\section{Conclusões e trabalhos futuros}

Considerando a pesquisa realizada no decorrer deste estudo e o desenvolvimento do repositório digital proposto para atender as necessidades de armazenamento e disseminação das produções científicas geradas pelo GP-NTI, pode-se dizer que todos os objetivos pré-definidos foram atendidos.

O estudo detalhado dos usos e modos de desenvolvimento de repositórios digitais é um assunto pouco abordado, principalmente tratando-se de texto em língua portuguesa. Mesmo tais sistemas sendo eficientes no objetivo de conservarem, gerirem e disseminarem as produções científicas e documentos gerados por instituições de fins diversos ocorre tal falta de literatura.

O fato de existir literatura um tanto escassa a respeito dos repositórios digitais enfatiza a importância e relevância deste trabalho, uma vez que o mesmo cumpre com os objetivos pré-definidos de estudar os repositórios digitais de forma a conhecer seus aspectos técnicos e teóricos, levando em conta sempre o uso em qualquer tipo de instituição que produza documentos digitais.

Os repositórios digitais são capazes, por meio do seu correto uso e divulgação, de transformar os conhecimentos tácitos em conhecimentos explícitos, ou seja, fazer com que conhecimentos gerados passem a serem socializados para desenvolvimento de novos conhecimentos, fazendo com que os documentos digitais gerados estejam sempre disponíveis aos interessados de uma maneira prática e eficiente e que também sejam preservados com o passar do tempo.

Também concluiu-se que os repositórios digitais podem ser muito eficazes dentro de instituições que não produzam produções científicas, mas que produzam documentos digitais referentes à administração e controle das instituições, pois com o uso eficaz destes sistemas tais documentos podem ser preservados. Preservando esses documentos é possível o reuso dos mesmos, o que pode evitar muito trabalho extra, e também permite que tais documentos estejam centralizados, algo que muitas organizações procuram, devido ao fato de muito do que se é produzido por seus membros ficar armazenados em lugares isolados, ou seja, não sendo disponibilizados a outros membros da organização que poderiam fazer bom uso dos mesmos, tornando os processos da organização cada vez mais eficientes.

Também pode-se prover a interoperabilidade entre sistemas na internet, sejam eles os repositórios digitais, ou também outros sistemas capazes de implementar os protocolos de interoperabilidade existentes. A implementação de tais protocolos possibilita que bases de dados distintas possam trocar informações, ou seja, uma base de dados pode fazer requisições ao banco de dados de metadados de outra base de dados, possibilitando assim o maior aproveitamento dos documentos digitais descritos nestas bases de dados. 
A partir deste trabalho pode-se se entender o funcionamento real dos repositórios digitais e conhecer os benefícios que os mesmos podem oferecer as instituições que os implementam, então pode-se pensar a partir daqui no desenvolvimento de repositórios digitais para todas aquelas instituições que desejem desenvolver um sistema eficiente e que será capaz, a partir de um bom desenvolvimento e boa divulgação, de armazenar seus documentos digitais, preservando-os no tempo e podendo aumentar significantemente a visibilidade e também a relevância de tais documentos.

\section{Referências}

Barton, M. R. (2005). Creating an institutional repository: LEADIRS workbook. Cambridge-MIT Institute. Disponível em: <www.ugr.es/ afporcel/construccion.pdf>. Acesso em 08 abr. 2009.

Crow, R. (2002). The case for institutional repositories: a SPARC position paper. The Scholarly Publishing and Academic Resources Coalition. Disponível em: $<$ http://www.arl.org/sparc/bm doc/ir_final_release_102.pd>. Acesso em 24 mar. 2009.

Lewis, S.; Yates, C. (2008). The DSpace Course - Introduction to Dspace. CADAIR,. Disponível em: <http://cadair.aber.ac.uk/dspace/handle/2160/617>. Acesso em 22 abr. 2009.

Lynch, C. A. (2003). Institutional repositories: essential infrastructure for scholarship in the digital age. Association of Research Libraries, n. 226. Disponível em: <www.arl.org/bm doc/br226ir.pdf>. Acesso em 23 abr. 2009.

NSDL. Summary of OAI Metadata Best Practices. Digital Library Federaton, 2005. Disponível em: <http://www.diglib.org/architectures/oai/imls2004/training/MetadataFinal.pdf>. Acesso em 30 mai. 2009.

Repositório institucional. In: GLOSSÁRIO. Instituto Brasileiro de Informação em Ciência e Tecnologia (IBICT), Brasília, (2007). Disponível em: $<$ http://dspace.ibict.br/index.php?option=com_content\&task=view\&id=43\&Itemid=7 7>. Acesso em 07 abr 2009.

Rodrigues, E. et al. (2004). RepositóriUM: criação e desenvolvimento do Repositório Institucional da Universidade do Minho. Serviços de Documentação da Universidade do Minho, Braga. Disponível em: <http://repositorium.sdum.uminho.pt/handle/1822/422>. Acesso em 02 abr. 2009.

Santos, J.; Teixeira, C.; Pinto, J. S. (2005) EABC: um repositório institucional virtual. Disponível em: <http://www.iadis.net/dl/final_uploads/200508P001.pdf >. Acesso em 02 abr. 2009. 